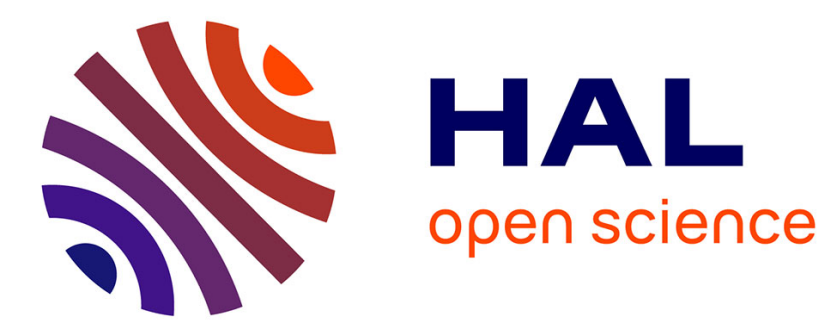

\title{
First Brønsted acid catalyzed asymmetric aldol reaction: a complementary approach to enamine catalysis.
}

Guillaume Pousse, Fabien Le Cavelier, Luke Humphreys, Jacques Rouden, Jérôme Blanchet

\section{- To cite this version:}

Guillaume Pousse, Fabien Le Cavelier, Luke Humphreys, Jacques Rouden, Jérôme Blanchet. First Brønsted acid catalyzed asymmetric aldol reaction: a complementary approach to enamine catalysis.. Organic Letters, 2010, 12 (16), pp.3582-5. 10.1021/ol101176j . hal-00871125

\section{HAL Id: hal-00871125 https://hal.science/hal-00871125}

Submitted on 8 Oct 2013

HAL is a multi-disciplinary open access archive for the deposit and dissemination of scientific research documents, whether they are published or not. The documents may come from teaching and research institutions in France or abroad, or from public or private research centers.
L'archive ouverte pluridisciplinaire HAL, est destinée au dépôt et à la diffusion de documents scientifiques de niveau recherche, publiés ou non, émanant des établissements d'enseignement et de recherche français ou étrangers, des laboratoires publics ou privés. 


\title{
First Brønsted acid catalyzed asymmetric aldol reaction: a complementary approach to enamine catalysis.
}

\author{
Guillaume Pousse ${ }^{a}$, Fabien Le Cavelier ${ }^{a}$, Luke Humphreys ${ }^{b}$, \\ Jacques Rouden ${ }^{a}$, and Jérôme Blanchet ${ }^{a *}$ \\ ${ }^{a}$ Laboratoire de Chimie Moléculaire et Thio-organique, ENSICAEN, Université de \\ Caen Basse-Normandie, CNRS, 6 boulevard du Maréchal Juin, 14050 Caen, France ; \\ ${ }^{b}$ Synthetic chemistry, Glaxosmithkline, Medecines Research Centre, Stevenage SG1 \\ 2NY, United-Kingdom \\ jerome.blanchet@ensicaen.fr
}

Received Date (will be automatically inserted after manuscript is accepted)

\section{ABSTRACT}

A syn enantioselective aldol reaction has been developed using Brønsted acid catalysis based on $\mathrm{H}_{8}$-BINOL derived phosphoric acids. This method affords an efficient synthesis of various beta-hydroxy ketones, some of which could not be synthesized using enamine organocatalysis.

Aldolisation is a powerful reaction to create carboncarbon bond. ${ }^{1}$ The coupling of two simple carbonyl compounds (aldehydes or ketones) leads to $\beta$-hydroxy carbonyl subunit. Since this structural moiety is present in numerous natural or synthetically useful products, continuous investigations have been devoted to this reaction over more than a century. While early experiments aimed at broadening the scope of the transformation, research in the last thirty years was focused on the stereoselectivity since two new

(1) (a) Modern Aldol Reactions; Mahrwald, R., Ed.; Wiley-VCH: Weinheim, Germany, 2004. (b) Mahrwald, R. Chem. Rev. 1999, 99, 1095-1120. stereogenic centers could be created during the course of the reaction. $^{2 \mathrm{a}}$

Recently, organocatalysis has emerged as a new tool to control the stereo outcome of aldolisation under very mild conditions with high level of selectivity. The use of strong bases is avoided, as well as metallic Lewis acids, preformed enolates such as silyl enol ethers or costly chiral auxiliaries. Since the seminal work of Hajos and Parrish, numerous proline derivatives and various polyfunctional amines were successfully evaluated to extend the usefulness of the organocatalysed cross aldol

(2) (a) Zlotin, S. G.; Kucherenko, A. S.; Beletskaya, I. P. Russ. Chem. Rev. 2009, 78, 737-784. (b) Geary, L. M.; Hultin, P. G. Tetrahedron: Asymmetry 2009, 20, 131-173. 
reaction. $^{2 b, 3}$ The efficiency of proline-based catalysts relies on the formation of a highly reactive enamine intermediate. Importantly only donors such as moderately hindered aldehydes and unsubstituted ketones gave good yields. In sharp contrast, acetophenone and fused cyclic aromatic ketones (indanone, tetralone...) derivatives are challenging substrates because they would involve twisted less reactive enamines intermediates due to low orbital overlap between the enamine double bond and the nitrogen lone pair (Figure 1). Other challenging substrates are $\alpha, \beta$-unsaturated ketones which may trap the amine catalysts through an irreversible 1,4-addition. Interestingly, while no organocatalyst is reported to be effective for the aldol reaction of $\alpha, \beta$-unsaturated ketones, only two recent contributions involving chiral zinc or rhodium complexes describe the successful use of methyl vinyl ketone and cyclic enones in asymmetric direct aldol reactions, thus witnessing the challenge represented by those substrates. ${ }^{4,5}$

Figure 1. Phosphoric acid catalyisis versus enamine catalysis.

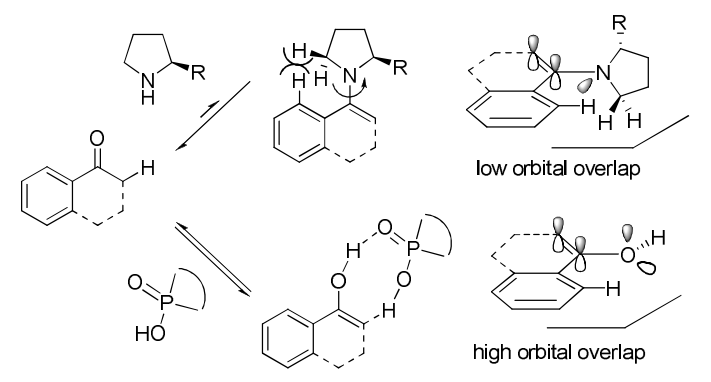

With this background in mind, we became interested by the alternative well-known acid catalysis. Chiral Lewis acids have been frequently used to control the stereoselectivity of the direct aldol reaction. ${ }^{6}$ Whitnessing the rapid growth of the use of chiral Brønsted, we embarked in an evaluation of those catalyst for the aldol reaction. ${ }^{7}$ To the best of our knowledge, among the rare case of carbonyl group activation ${ }^{8}$ such strategy has been ignored so far.

(3) Mukherjee, S.; Yang, J. W.; Hoffmann, S.; List, B. Chem. Rev. 2007, 107, 5471-5569.

(4) Trost, B. M.; Shin, S.; Sclafani, J. A. J. Am. Chem. Soc. 2005, 127, 8602-8603.

(5) Mizuno, M.; Inoue, H.; Naito, T.; Zhou, L.; Nishiyama, H. Chem. Eur. J. 2009, 15, 8985-8988.

(6) (a) Trost, B. M.; Silcoff, E. R.; Ito, H. Org. Lett. 2001, 3, 24972500. (b) Kumagai, N.; Matsunaga, S.; Kinoshita, T.; Harada, S.; Okada, S.; Sakamoto, S.; Yamaguchi, K.; Shibasaki, M. J. Am. Chem. Soc. 2003, 125, 2169-2178.

(7) (a) Akiyama, T. Chem. Rev. 2007, 107, 5744-5758. (b) Terada, M. Chem. Commun. 2008, 35, 4097-4112.

(8) (a) Xu, S.; Wang, Z.; Wang, X.; Zhang, X.; Ding, K. Angew. Chem., Int. Ed. 2008, 47, 2840-2843. (b) Rueping, M; Nachtsheim, B. J.; Moreth, S. A.; Bolte, M. Angew. Chem., Int. Ed. 2008, 47, 593-596.; (c) Rowland, E. B.; Rowland, G. B.; Rivera-Otero, E.; Antilla, J. C. J. Am. Chem. Soc., 2007, 129, 12084-12085. (d) Rueping, M.; Ieawsuwan, W.; Antonchick, A. P.; Nachtsheim, B. J. Angew. Chem., Int. Ed. 2007, 46, 2097-2100.
Initially we screened various Brønsted acids and substrates to identify suitable conditions to further investigate this strategy. Cyclohexanone was selected as a model nucleophile while ethyl glyoxylate was found to be the most reactive electrophile. ' Various conditions and catalysts were then tested (Table 1). BINOL derived phosphoric acid rac-3a was rapidly identified as a satisfying catalyst candidate when excess ketone was used (Table 1, entry 5). The reactions carried out under equivalent molar amount of reagents or excess of glyoxylate afforded the aldol product in slightly lower yields. Surprisingly, concerning the required acidity of the catalyst, stronger acids such as $\mathbf{1}$ and $\mathbf{2}$ behaved sluggishly (Table 1, entry 3 and 4).

Table 1. Optimization of the aldol reaction conditions.

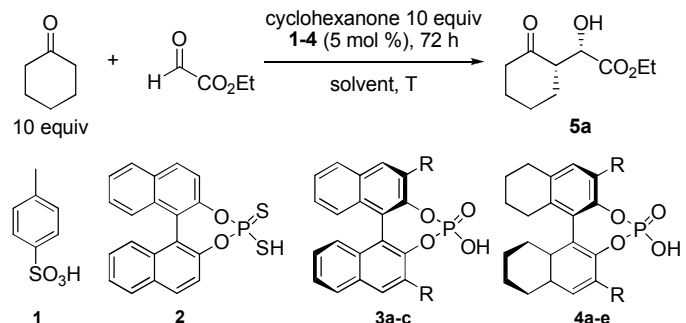

\begin{tabular}{|c|c|c|c|c|c|c|}
\hline entry $^{a}$ & catalyst & $\mathrm{R}$ & $\mathrm{T}\left({ }^{\circ} \mathrm{C}\right)$ & $\begin{array}{l}\text { Yield } \\
(\%)^{a, b}\end{array}$ & syn:antic & $\begin{array}{c}\text { er } s y n^{d} \\
(\%)\end{array}$ \\
\hline 1 & none & - & 20 & 0 & - & - \\
\hline 2 & $\mathrm{CF}_{3} \mathrm{CO}_{2} \mathrm{H}$ & - & 20 & 58 & $35: 65$ & - \\
\hline 3 & 1 & - & 20 & 18 & $50: 50$ & - \\
\hline 4 & rac-2e & - & 20 & 40 & $50: 50$ & - \\
\hline 5 & rac-3ae & $\mathrm{H}$ & 20 & 75 & $50: 50$ & - \\
\hline 6 & 3b & 1-naphthyl & 20 & 70 & $55: 45$ & $72: 28$ \\
\hline 7 & $3 c$ & $2,4,6-i \mathrm{Pr}-\mathrm{C}_{6} \mathrm{H}_{2}$ & 20 & 78 & $80: 20$ & $85: 15$ \\
\hline 8 & $4 a$ & $\mathrm{Ph}$ & 20 & 60 & $55: 45$ & $75: 25$ \\
\hline 9 & $4 b$ & 1-naphthyl & 20 & 65 & $60: 40$ & $73: 27$ \\
\hline 10 & $4 c$ & 9-phenanthryl & 20 & 78 & $55: 45$ & $76: 24$ \\
\hline 11 & 4d & $2-i \mathrm{Pr}-\mathrm{C}_{6} \mathrm{H}_{4}$ & 20 & 77 & $66: 33$ & $81: 19$ \\
\hline 12 & $4 e$ & $2,4,6-\mathrm{Me}-\mathrm{C}_{6} \mathrm{H}_{2}$ & 20 & 72 & $55: 45$ & $86: 14$ \\
\hline 13 & $4 e$ & $2,4,6-\mathrm{Me}-\mathrm{C}_{6} \mathrm{H}_{2}$ & 0 & 58 & $60: 40$ & $91: 9$ \\
\hline 14 & $4 e$ & $2,4,6-\mathrm{Me}-\mathrm{C}_{6} \mathrm{H}_{2}$ & $0^{f}$ & 55 & $70: 30$ & $93: 7$ \\
\hline 15 & $4 e$ & $2,4,6-\mathrm{Me}-\mathrm{C}_{6} \mathrm{H}_{2}$ & $0^{f g}$ & 50 & $70: 30$ & $95: 5$ \\
\hline 16 & $3 c$ & $2,4,6-i \mathrm{Pr}-\mathrm{C}_{6} \mathrm{H}_{2}$ & $0^{f}$ & 50 & $80: 20$ & $89: 11$ \\
\hline
\end{tabular}

${ }^{a}$ A concentration of $0.4 \mathrm{M}$ was used. ${ }^{b}$ Isolated yield. ${ }^{c}$ Determined by ${ }^{1} \mathrm{H}$ NMR of the crude mixture. ${ }^{d}$ Determined by chiral HPLC. ${ }^{e}$ Racemic catalyst was used. ${ }^{f}$ A concentration of $10 \mathrm{M}$ was used. ${ }^{g}$ Catalyst $4 \mathbf{e}$ was recycled from previous experiments.

In order to induce high selectivity in asymmetric transformations when using BINOL derived phosphoric acids, the chiral BINOL backbone must be substituted by bulky aromatics on the 3,3' positions. Several 3,3'disubstituted- $\mathrm{H}_{8}$-BINOL derived phosphoric acids were

(9) Other electrophiles were tested (2-methylpropanal, 1-butanal, chloral, 2- and 3-pyridine carboxaldehyde, benzaldehyde, phenyl glyoxal) and only traces of product was detected. Ethyl trifluoropyruvate delivered $42 \%$ yield. 
thus prepared according to an improved procedure developed in our laboratory. ${ }^{10}$

(10) Pousse, G.; Devineau, A.; Dalla, V.; Humphreys, L.; Lasne, M.C.; Rouden, J.; Blanchet, J. Tetrahedron, 2009, 65, 10617-10622. 
Table 2. Scope of the aldol reaction. Variation of the electrophile and the nucleophile.

\begin{tabular}{|c|c|c|c|c|c|c|c|}
\hline entry $^{a}$ & Ketone & Major product & & Conditions $^{a}$ & Yield $^{b}$ & syn:anti ${ }^{c}$ & er $s y n^{d}$ \\
\hline 1 & & & $5 \mathbf{b}$ & $10 \mathrm{M}, 0^{\circ} \mathrm{C}^{\mathrm{e}}$ & 42 & $70 / 30$ & $92: 8$ \\
\hline 2 & & & $5 c$ & $10 \mathrm{M}, 0^{\circ} \mathrm{C}^{\mathrm{f}}$ & 51 & $65 / 35$ & $89: 11$ \\
\hline 3 & & & 6 & $10 \mathrm{M}, 20^{\circ} \mathrm{C}$ & 50 & $85 / 15$ & $83: 17$ \\
\hline 4 & & & 7 & $5 \mathrm{M}, 10^{\circ} \mathrm{C}$ & 44 & $50 / 50$ & $85: 15$ \\
\hline 5 & & & 8 & $10 \mathrm{M}, 10^{\circ} \mathrm{C}$ & 54 & $75 / 25$ & $85: 15$ \\
\hline 6 & & & 9 & $0.4 \mathrm{M}, 50^{\circ} \mathrm{C}$ & 86 & $70 / 30$ & $80: 20$ \\
\hline 7 & & & 10 & $10 \mathrm{M}, 10^{\circ} \mathrm{C}$ & 83 & $90 / 10$ & $83: 17$ \\
\hline 8 & & & 11 & $10 \mathrm{M}, 20^{\circ} \mathrm{C}$ & 52 & - & $81: 19$ \\
\hline 9 & & & 12 & $5 \mathrm{M}, 10^{\circ} \mathrm{C}$ & 60 & $70 / 30$ & $74: 26$ \\
\hline 10 & & & 13 & $10 \mathrm{M}, 10^{\circ} \mathrm{C}$ & 50 & $85 / 15$ & $85: 15$ \\
\hline 11 & & & 14 & $0.4 \mathrm{M}, 50^{\circ} \mathrm{C}^{e}$ & 78 & $55 / 45$ & $78: 22$ \\
\hline 12 & & & 15 & $5 \mathrm{M}, 10^{\circ} \mathrm{C}$ & 79 & $95 / 5$ & $88: 12$ \\
\hline 13 & & & 16 & $10 \mathrm{M}, 20^{\circ} \mathrm{C}^{g}$ & 70 & $70 / 30$ & $88: 12$ \\
\hline 14 & & & 17 & $0.4 \mathrm{M}, 50^{\circ} \mathrm{C}^{g}$ & 70 & - & $79: 21$ \\
\hline
\end{tabular}

${ }^{a}$ Reaction conditions: ethyl glyoxylate, ketone (10 equiv), $4 \mathrm{e}(5 \mathrm{~mol} \%)$, toluene. ${ }^{b}$ Isolated yield. ${ }^{c}$ Determined by ${ }^{1} \mathrm{H}$ NMR. ${ }^{d}$ Determined by chiral HPLC. ${ }^{\mathrm{e}}$ benzyl glyoxylate was used ${ }^{\mathrm{f}}$ isopropyl glyoxylate was used ${ }^{g} 20 \mathrm{~mol} \%$ 4e was used.

The introduction of aromatic groups with variable steric hindrance had a strong influence on both diastereoand enantioselectivity. Phosphoric acid 4a with a phenyl substituent afforded almost no diastereoselectivity and an average enantioselectivity (er 75:25) for the syn diastereoisomer (Table 1, entry 8), whereas hindered acids $4 \mathbf{b}\left(\mathrm{Ar}=2,4,6-i \mathrm{Pr}-\mathrm{C}_{6} \mathrm{H}_{2}\right)$ and $3 \mathbf{e}(\mathrm{Ar}=2,4,6-\mathrm{Me}-$ $\mathrm{C}_{6} \mathrm{H}_{2}$ ) led respectively to improved diastereoselectivity in favor of the syn isomer ( $\mathrm{dr}$ syn : anti 80:20, Table 1, entries 7), and enantioselectivity (er 86:14) for the major syn isomer (Table 1, entry 12).
Next, we screened the reaction conditions to optimize the yield and selectivity of the aldol product. Among the various non protic solvent tested (toluene, xylene, THF, $\mathrm{Et}_{2} \mathrm{O}, \mathrm{Bu}_{2} \mathrm{O}, \mathrm{CH}_{2} \mathrm{Cl}_{2}, \mathrm{CH}_{3} \mathrm{CN}$ ), toluene was identified to afford the highest diastereo- and enantioselectivity at room temperature (see supplementary material). Interestingly, reactions could be performed at $50{ }^{\circ} \mathrm{C}$ with little erosion of enantioselectivity (data not shown). Decreasing the reaction temperature had a beneficial impact on the overall selectivity (Table 1, entries 13 and 16). An optimal amount of $5 \mathrm{~mol} \%$ catalyst was 
determined while $1.5 \mathrm{~mol} \%$ led to slightly decreased selectivity and $10 \mathrm{~mol} \%$ to no improvement (data not shown). Carrying out the reaction near solventless conditions, using only the toluene provided by the commercial solution of the glyoxylate, led to a significant improvement of both reaction rates and selectivity ( $\mathrm{dr} s y n$ : anti, 70:30 and 93:7 er for the syn isomer, Table 1, entry 14).

Recycled catalyst, easily recovered by column chromatography in $80 \%$ yield, performed with the same level of selectivity (Table 1, entry 15). Absolute configuration of the main isomer was acertained by comparison with litterature data. ${ }^{11}$

Interestingly, the observed diastereoselectivites were moderated in favor of the syn diastereoisomer, so we decided to explore the generality of this new Brønsted acid catalyzed aldolisation.

First, the reaction scope was probed by changing the nature of the glyoxylate partner. Isopropyl and benzylic glyoxylates led to slightly lower selectivity and reactivity (Table 2, entries 1-2). Pyrrolidine glyoxamide failed to react under selected reaction conditions.

Finally we investigated several nucleophile partners of the reaction. Simple ketones such as pentan-2-one, tetrahydrothiopyran-4-one, tetrahydropyran-4-one and cyclopentanone gave slightly lower selectivities than cyclohexanone under optimized reaction conditions (Table 2, entry 3-6). Since those substrates including cyclohexanone are routinely used in aldol reactions, we were most interested to test compounds that are known to be challenging, particularly when enamine catalysis is involved.

Phenylacetone afforded the expected branched aldol product with complete regiospecificity with 83:17 er for the syn isomer at $10{ }^{\circ} \mathrm{C}$ (Table 2, entry 7). More interestingly acetophenone, 4-chromanone, tetralone and crowded 2-methyltetralone were found to be suitable substrates, giving average to good yields of aldol products with up to $85: 15$ er for the major syn isomer (Table 2, entry 8-11). Importantly those substrates have never been reported in any organocatalyzed aldol reactions, probably due to the difficult formation and poor reactivity of the enamine intermediate if one would use a proline derivative as catalyst. Although lower reactivity was found with these compounds, a quaternary center was formed by the condensation of 2-methyltetralone with ethyl glyoxylate, such a reaction being usually carried out under Mukayama's conditions. With indanone only the syn isomer was isolated with $88: 12$ er at $10{ }^{\circ} \mathrm{C}$ (Table 2, entry 12).

Encouraged by the previous results we next tested $\alpha, \beta$ unsaturated ketones using Brønsted acid catalysis. We found that cyclohexenone and 3-penten-2-one delivered the expected aldol products in $70 \%$ yield and up to $88: 12$ er at $50{ }^{\circ} \mathrm{C}$ (Table 2, entry 13 and 14). No compound corresponding to a possible vinyloguous reaction was observed. Notably, no elimination by-product was

(11) See supplementary information for more details. detected in spite of the known instability of such aldol products. These two examples represent rare cases of an asymmetric direct aldol reactions with enones, without the recourse to their silyl enol ethers derivatives.

In summary we have uncovered the first asymmetric Brønsted acid catalyzed direct aldol reactions. Moderate to excellent diastereo- and enantioselectivity have been achieved using chiral $\mathrm{H}_{8}$-BINOL derived phosphoric acids (up to 95:5 dr and 95:5 er) which may render this approach synthetically attractive for the synthesis of more complex molecule. The sense of the relative stereoselection is the opposite as the one in similar proline catalyzed reactions, favoring the syn isomer. ${ }^{12}$ These results clearly demonstrate the complementary character of Brønsted acid catalysis towards enamine (proline) catalysis. In particular, many unreactive substrates in enamine-type organocatalysis are affording the aldol product under those conditions. Northeworthy are the examples of 2-methyltetralone and enones . Finally, the catalyst can be easily recycled with equivalent performances. Studies of the mechanism, and synthetic applications of this reaction are currently under investigation.

Acknowledgment We gratefully acknowledge GlaxoSmith-Kline and CNRS for a fellowship to GP, ANR "MESORCAT" (CP2D program), Région BasseNormandie and the European Union (FEDER funding) for financial supports.

Supporting Information Available: Experimental procedure, characterization data, HPLC charts and copies of NMR spectra for all new compounds. This material is available free of charge via the Internet at http://pubs.acs.org.

(12) Only in rare cases organocatalysts were reported to be general syn-selective aldol catalyst. (a) Luo, S.; Xu, H.; Li, J.; Zhang, L.; Cheng; J.-P. J. Am. Chem. Soc. 2007, 129, 3074. (b) Kano, T.; Yamaguchi, Y.; Tanaka, Y.; Maruoka, K. Angew. Chem., Int. Ed. 2007, 46, 7606-7608. $\alpha$-hydroxy ketones are known to deliver syn selectivity, see (c) Ramasastry, S. S. V., Zhang, H., Tanaka, F.; Barbas III, C. F. J. Am. Chem. Soc. 2007, 129, 288-289. (d) Palyam, N.; Majewski, M. J. Org. Chem. 2009, 74, 4390-4392. 